\title{
Landform mapping of Okinoshima island and sea bed of Munakata city
}

\author{
Takahito KUROKI ${ }^{\mathrm{a}}{ }^{*}$ \\ ${ }^{a}$ University of Teacher Education Fukuoka, kuroki0@fukuoka-edu.ac.jp \\ * Corresponding author
}

Keywords: Okinoshima island, Landform classification, Airborne laser scanner data

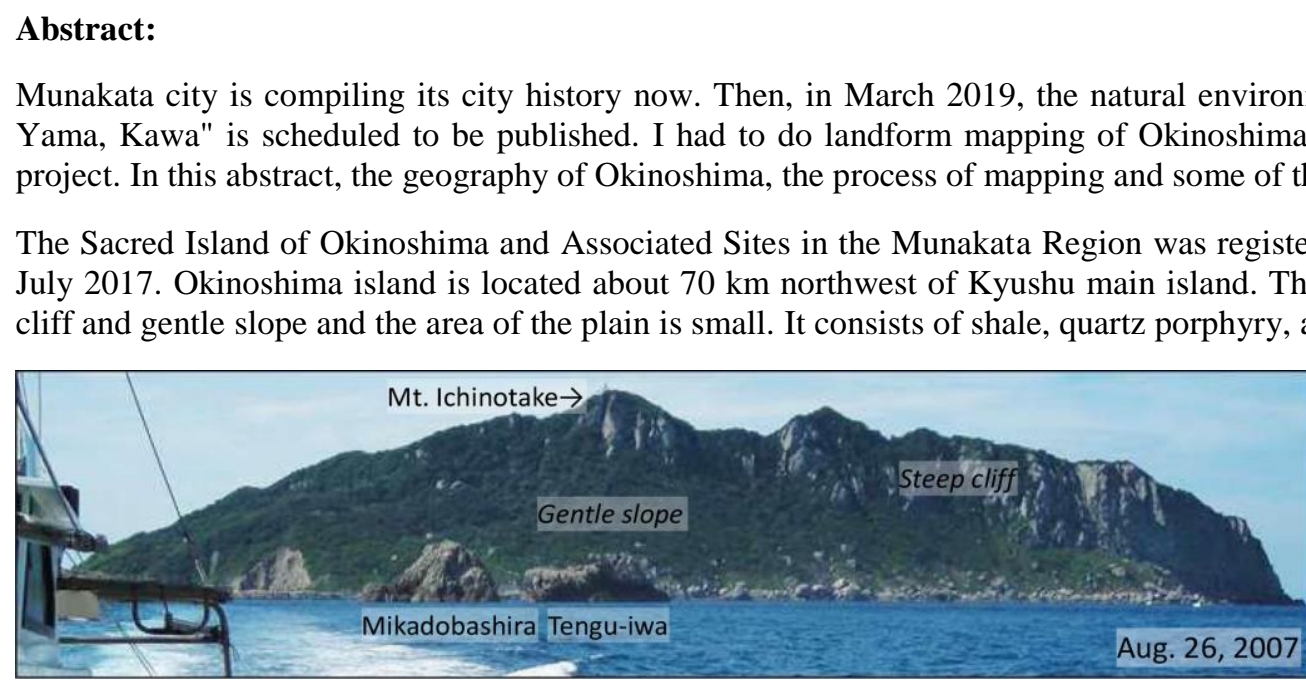

Figure 1. Landscape of Okinoshima island from the south.

Fig. 1 shows the landscape of Okinoshima island from the south. The highest peak is Mt. Ichinotake, the rock on the left is Mikadobashira and the rock on the right is Tengu-iwa. There is a holy place, Okitsu-miya of Munakata Taisha at the foot of the island. Residents have unwritten taboos that forbid actions such as removing anything from the island, or revealing anything seen or heard there.

Maps of land and sea bed were made by various kinds of geographic information by using GIS. They are ground elevation map, slope map, relief map and 3D image. Fundamental geospatial data of GSI (Geospatial Information Authority of Japan), map information related to isobaths of JHA (Japan Hydrographic Association) and airborne laser scanner data of Munakata city are used as the geographic information.

Landform classification map was made by interpretation of each map and field survey. Classified landforms are crest, dissected valley, steep cliff, landslip lobe, talus cone, seaside and man-made land. Farthermore, geologic and topographic lineaments were interpreted.

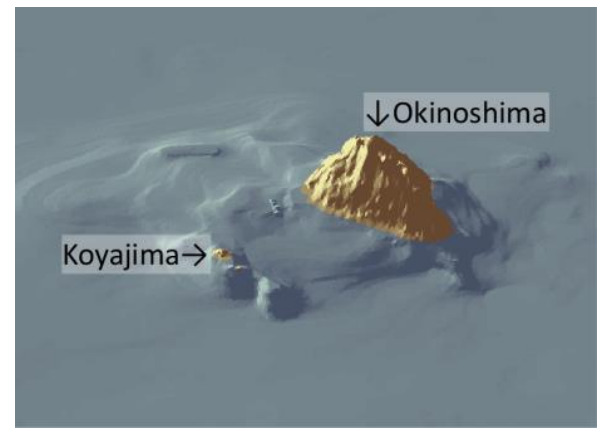

Figure 2 3D model of Okinoshima area from the east

Fig. 2 shows the 3D image of Okinoshima from the east. It can be identified that the height of Okinoshima is about 340 $\mathrm{m}$ above the flat sea bed. The topography between Okinoshima and Koyajima under the sea surface, is a shallow flat 
table in the west side and a concave area inclining to the east in the east side. The shape of the set of islands is like a horseshoe-shaped caldera.

In this poster presentation, I would like to introduce that we can understand the landform and its formative process of Okinoshima where access is restricted from the analysis and reference of such maps by GIS. 